\title{
Hospital Closures and Community Care
}

\section{Correspondence between the National Schizophrenia Fellowship and the Minister for Health}

Following the publication of correspondence between the then Minister for Health, Mr Kenneth Clarke, and the National Schizophrenia Fellowship (Bulletin, March 1985, 9 , 49-55), we are now publishing the concluding letters in this exchange of correspondence. (Mrs Joyce Major has been succeeded by Mr R. N. Lines as Chairman of the NSF.)

31 OCTOBER 1984

Dear Mr Clarke

We are extremely grateful for your letter of 2 October addressed to Mrs Major (from whom I have now taken over as chairman); particularly for the final paragraph, in which you say that it is healthy to hammer out our differences-differences in approach, rather than in objectives. In this spirit we make some comments on your letter with, we hope, responsibility, both in the sense of trying as far as possible to avoid bias, and in the sense of speaking for all sufferers-with or without relatives-from what, by prevalence, duration and severity, is the major mental illness.

In our letter of 2 July we referred to the confusion amongst district health authorities over probable numbers of long-stay patients. You do not refer to this.

In the past year we have seen and commented on a large number of district health authorities' planning and consultative papers. We have been glad to find that most of them now at least recognize that long-stay patients exist and will continue to exist. But we have been dismayed that authorities - with rare exceptions- have no idea how to estimate the numbers for which provision will have to be made. We have given a good deal of attention to this in our comments; but we have only been in touch with perhaps a quarter of all district health authorities-and, since these were the ones that responded to our request for sight of documents-we may perhaps be forgiven for supposing that most of the rest would be no more enlightened. The effects of misjudging the size of the problem must range from wasted resources to suicides.

In July 1983, Lord Glenarthur told the House of Lords: 'There are no norms and we see no value in minimum standards set centrally'. We welcomed this. Yet district health authorities continue quoting a variety of 'norms', often of undisclosed provenance and usually unrelated to local needs. We agree that standard figures cannot be set centrally; districts vary very widely. But we would like to believe that your Department is monitoring districts' arithmetic. We do not have a great deal of confidence in regional ability to do thisagain with rare exceptions. The latest official paper forecasting numbers (national averages) was a great advance on its disastrous predecessors; and gave some guidance to local planners on how to make their own forecasts (Robertson, March 1981). It was said to have been distributed to regional statisticians; but hardly any of the papers we have seen make any reference to it.
Lord Glenarthur, in a letter of 3 August 1983 to Richard Needham, MP, said: 'We are hoping to start work soon on reviewing and updating our methods of bed forecasting'; and added that he had asked officials to take our detailed points into account. In a later letter he said that such forecasting will still be subject to various limitations. We tried-in our 1979 pamphlet 'How Many Places?'-to suggest a way of reducing these limitations. We must repeat that our request for stringent scrutiny of our suggestions elicited no response from the Department.

With so much initiative left to district health authorities, you rightly stress the need for trying to influence planning at local levels. We are an expanding, but comparatively young organization, and our effective local groups, though increasing, are still sited in less than half the health districts. Those competent to scrutinize local plans are probably fewer still; and to continue to do this, with any thoroughness, from our centre is beyond its capacity. This is part of our excuse for writing to you again at this critical stage in the planning process.

Your letter lays some weight on the intention 'that plans are kept under review to enable them to be modified as circumstances change'. (Are we perhaps unduly gloomy in seeing some room for conflict here with your determination, expressed in your earlier letter, that plans once decided should be 'pushed through energetically and effectively'?) One of the most important 'circumstances'-which we hope will change-is present ignorance of what will turn out to be the least unsatisfactory arrangements, particularly for the severely chronically ill. A trial and error process is necessarily slow; and time is also needed for spreading the lessons of comparative success. Your letter speaks of a small-scale initiative to improve co-ordination of 'after-care' for schizophrenia and adds that 'it will take some time before we can hope for any results'. Exactly.

The need for time for testing, evaluation and proliferation of worthwhile schemes (as well as for National Schizophrenia Fellowship expansion to the point where we can, in your words, 'play a full part in the local discussion process') causes our members what might be described euphemistically as grave concern, but more accurately as panic.

Your suggestion that the figures illustrate 'that closures are a consequence of discharges, rather than the other way round' needs a lot of qualification. Since 1962, discharges-and refusals to admit-have gone on under powerful pressures to reduce numbers, often with scant regard for the fate of patients; assessment in hospital settings of capacity for life outside is notoriously unreliable. The margin between occupied and available beds (see below on turnover interval and other factors; also on waiting lists) is no indication of room for closures. The argument that 'in terms of statistics health authorities could close twelve 800 -bedded hospitals tomorrow, and leave in-patient numbers still at their present 
level' would only be true if all movement in and out were to cease.

You say, 'We would not give approval to the closure of a mental illness hospital unless detailed plans were in existence to replace the services by those better services...' But plans-even if anyone were sure what adequate replacements should be like-can go awry. Services in working ordertried, proved and financed-are essential.

You mention joint financing without saying what fraction of it has gone to mental illness services. You also say that the money saved on the running of St Wulstan's will be spent on developing 'patient services' in the region. We would like to be assured that these will all be services for the mentally ill.

In answer to our fears about the effects of closing St Wulstan's, we have been emphatically assured that ample provision exists in the region for care appropriate to the patients' needs. You now say that the region has been asked to arrange for individual assessments of the form of care needed. There could hardly, it seems to us, be a clearer demonstration of a decision on closure preceding the acquisition of information required for judging whether adequate alternatives exist or are on the way. We find it hard to believe that the provision of services of all kinds is so abundant that, whatever the proportions of different kinds of need revealed by the assessment may be, they will be met. May I repeat the request I made to you at the MIND Conference earlier this month to ensure that, in the matter of hospital closures/community care, the horse is put firmly in front of the cart, and kept there?

We must apologize for failing to realize the width of the gap between available and occupied beds. In our preoccupation with the figures of long-stay patients we forgot the greater influence of turnover interval on the occupancy of shorter stay beds. Robertson puts this interval at an average ten days, giving an occupancy rate of 80 per cent for shorter stay beds (depending on local policy for transfer from district general hospital units). On Robertson's forecasts for 1991, we reckon that this would mean an average (including long stay) of about 11 per cent vacant beds. From the tables you gave us the present fraction of vacant beds appears to average 15 per cent; but there are of course other factors at work besides turnover time, e.g. alterations and maintenance, staff shortages perhaps ('resource occupied bed targets' is one regional health authority's beautiful phrase, meaning reduction of beds to meet a predetermined ratio to available ancillaries). At any rate, the margin of vacant beds is not incompatible with the frequent experience of our members of being told that no bed is available when required.

The question of waiting lists is also relevant. We are surprised that after discussion with North West Thames you were unable to confirm an increase of mental illness waiting lists. The reference is Table 49 in their document Regional Strategy-Information Base and Planning Methodology (April 1983).

We believe that your objectives for the treatment and care of mental illness sufferers are broadly the same as our own. We however view them from an immediate and pressing perspective, and we have less faith perhaps than you have in the capacity, often even the will, of local health authorities to make the right plans, and finance them. In my own county, Buckinghamshire, a start is being made in the right direction, but much more pressure on all health authorities, and also local authorities, seems to us to be necessary. Above all, substantial bridging finance and positive incentive will be essential, to enable a satisfactory transition to be made from the present conditions to acceptable levels of treatment and care in hospitals when needed, and of care in the community where that is more appropriate.

I end as I began by thanking you for agreeing to this dialogue, which I hope we may continue, as the development of needs and plans unfolds.

Yours sincerely

R. N. LINES

17 APRIL 1985

DeAr Mr Lines

Thank you again for your letter of 31 October and also for your further letter of 24 February. I am sorry you have not had an earlier reply.

May I confirm straightaway that I am happy for this letter and my earlier letters to the Fellowship to be circulated/ published as you wish.

You raised a number of points in your letter of 31 October on which I would like to respond. Firstly, you said that my reply of 2 October did not refer to your experience of confusion amongst district health authorities over probable numbers of long-stay patients. The Fellowship's earlier letter of 2 July said 'we are . . . concerned with the severely chronically ill, who include so many of our patients, and especially the new long-stay. We find very great confusion and difference of opinion about probable numbers, and vagueness of ideas about what to do with them'. In my response I said that I appreciate your longstanding concern with the chronically mentally ill and hope that all the discussions that are going on now as part of the planning process will remove some of the vagueness of ideas the Fellowship has encountered. Perhaps I should have spelled out more clearly that my sentiments also applied to long-stay patients.

Some work has been done on revising and updating our methods of bed forecasting. This will be continued with a view to providing more guidance to NHS planners.

You asked about the money from St Wulstan's. I can only repeat that it is for local health authorities to decide exactly how they allocate their resources. Authority members are best placed to assess local priorities, weigh the issues involved and make decisions in the light of available resources and sometimes conflicting needs. The West Midlands Regional Health Authority has requested its 22 district health authorities to free up a total of $£ 40$ million revenue over the fiveyear period 1984-85 to 1988-89. This amount will be redistributed to priority services and, in particular, services for the mentally ill will benefit by about $£ 8$ million.

As regards the future care of the former patients at $\mathrm{St}$ Wulstan's and your general point about hospital closures/ community care, I repeat what I said in my earlier letter. We would not give approval to the closure of a mental illness 
hospital unless detailed plans were in existence to replace its services by better services.

Thank you for drawing my attention to Table 49 in North West Thames' April 1983 regional strategy document. I am sorry that the document was not checked when we were looking at your earlier letter.

I agree that bridging finance may be needed to ensure that there is no financial reason to delay an appropriate transfer from hospital to community care. We have, in fact, raised this with regional treasurers and I am pleased to say that several worthwhile schemes have been introduced or developed and we aim to ensure that each region can benefit from the experience of others.

I have replied only to those points where it seemed you particularly wanted a reply because, as you said, our differences related to questions of approach rather than objectives. On those points I have not specifically responded to, I have noted your views.

I wish you well in your time as Chairman.

Yours sincerely

Kenneth Clarke

17 JULY 1985

\section{Dear Mr Clarke}

I owe you an apology for not having previously acknowledged and thanked you for your letter of 17 April. Your letter rounded off our correspondence, as you no doubt intended it to do, but I think it may be useful to send you for information a copy of a short note about the probable number of long-stay patients for whom provision will be needed, and which we hope to circulate to all health authorities. I have waited for this to be finalized, and now enclose a copy.

We are very grateful for your permission to publish this series of letters which we have exchanged.

I was encouraged by your statement that closure of a mental illness hospital 'would not be approved unless detailed plans were in existence to replace its services by better services'. I feel bound however to comment that no one can live in a plan. In the light of the Select Committee Report we do not need to labour the point that approval of hospital closures (or further rundown) cannot be justified by the existence only of plans for alternatives; no reduction should take place until the alternatives are ready. Please see the Report's Recommendation 2, entitled 'Cart and horse'.

Yours sincerely

R. N. LINES

\section{Long-Term Patient Numbers}

We use the expression 'long-term patient' to describe one who, whether in hospital or elsewhere, needs a great deal of supervision and/or nursing care. We use 'long-stay patient' for the smaller category in hospital or equivalent health service institution. The great majority of long-term who are not long-stay are at present cared for by relatives, if at all; a small fraction are in staffed homes provided by the voluntary sector, or are in local authority hostels.

In 1984 we were grateful to DHAs who responded to our earlier request for sight of planning documents. We were concerned to find in these a high proportion of unrealistic approaches to the problem of forecasting needs for places for long-stay patients. We hope that our concern will be accepted as sufficient explanation of our rushing in with the following comments where the DHSS apparently fears to tread.

Forecasting numbers of places needed for long-stay patients in hospital or equivalent is a relatively straightforward matter for a district health authority. 'Relatively', because districts have up-to-date figures of actual numbers of such patients, and can see the likely effects of their own policies. In contrast, forecasting average needs for wider areasregions and, still more, the whole country-is complicated by having to conflate figures from smaller areas (which may use different categories); and by inevitable time lag, so that recently developed trends are not apparent (see below on the Eason and Grimes forecast).

The DHSS is therefore right to have doubts about the value of central guidance; though they may have gone too far if this means abandoning the attempt to compile actual national averages (see below; and the reference to 'statistical lacunae' in the Select Committee report on community care).

District needs vary very widely. The value of a regional or national average is only that a large difference between the calculated district need and the average may stimulate enquiry into the reasons. These may include demographic factors-including the nature as well as the size of net inward or outward migration (outward migration for conurbations leaves behind a higher proportion of vulnerable people; inward migration to rural areas has the opposite effect). The district's admission and discharge policies may differ from the average. And forecasting is not an exact science: errors creep in.

We find that calculations by health authorities of numbers of places required are often confusing and confused. Causes of this include: (a) differing definitions; (b) adoption of unsubstantiated 'norms'; (c) erroneous calculations; and (d) erroneous beliefs.

\section{Differing definitions}

There are differences about categories to be included in the longstay. Some authorities include elderly severely mentally ill (ESMI) or dementia cases; others do not. Some include non-dementia cases over 65; others not. As long as the choice is clearly stated, and borne in mind by critics, this is a relatively small inconvenience.

Greater and more insidious confusion is caused by vast variation in the date taken for the division between 'old' and 'new' long-stay patients. This is not only inconvenient for making valid comparisons; it almost invariably results in classifying as 'old'-and therefore assumed to be rapidly declining in numbers-people who, under the original and reasonable definition in the White Paper, are new. The DHSS has recently pointed out that no sharp line of division can be drawn. This is true; but for practical purposes-as long as appreciable numbers of the 'old' remain-there is some use in selecting a cut-off date (in spite of exceptions on both sides of the line). The intention of the 1975 White Paper, Better Services for the Mentally III, was that 'old long-stay' should mean patients admitted too long ago to benefit quickly enough from modern treatments. The cut-off date implied in the White Paper is the end of 1966 . This is the latest reasonable date conforming to the definition.

Authorities-including central statisticians-have selected a wide variety of cut-off dates, almost all later than the White Paper suggested (in one case, the end of 1983), thus underestimating the numbers of new long-stay in any valid sense.

Some authorities add gratuitous confusion by counting as new longstay only those with over one and under five years' stay: while others count only those with over five years.

\section{'Norms'}

The DHSS said in 1983 'there are no norms'. Nevertheless, many authorities, instead of doing their own sums, fall back on alleged norms-often without giving the source. One authority was reduced to 
stating needs according to three different norms, with a ratio of three to one between extremes.

As already said, forecasts of national averages are, in any case, not directly relevant to regions' needs, still less to those of districts.

One particularly persistent myth is that the White Paper announced a 'norm' of 17 long-stay beds per 100,000 population. The White Paper said in fact that no guidance could be given (4.64); more research was needed (4.56). The paper mentioned, but did not endorse, the figure of 17 as one estimate (average) for a limited section of long-term patients (4.53).

Other authorities take the Eason and Grimes 1976 (erroneous) forecast for 1981 of 33 beds per 100,000 (excluding elderly severely mentally ill-ESMI) as applicable for all time and in all areas.

\section{Erroneous calculations}

In addition to errors resulting from ill-defined categories and irrelevant, misunderstood or mythical 'norms', there are-not surprisingly arithmetical mistakes. These are especially liable to infect forecasts of likely rates of accumulation of long-term patients. The concept of accumulation is itself only an analytical device. In the real world, longterm patients are not accumulating; they are already there (whether in or out of hospital, whether under treatment or not). With the exception of comparatively few survivors from a fraction of those admitted to hospital before 1967, their total is unlikely to change-except for demographic reasons-until there is a new major improvement in treatment.

The only use of the concept of accumulation is in conjunction with that of an arbitrary baseline and extrapolation from apparent trends of historical rates of admissions, discharges and deaths. It may help to provide a rather shaky cross-check to calculations based on actual current numbers of long-stay patients in hospital. And, indirectly, it can be used to get some guide to a part of the population of long-term patients 'in the community', i.e. the part consisting of those who have been in hospital at some time. (The other part, consisting mostly of those who have never been in touch with 'the services', can only be guessed at until properly investigated.)

\section{Erroneous beliefs}

(1) Although many health authorities have come to recognize that the long-term patient is a 'health' responsibility whether in or out of hospital, some still seem to believe that, once out, he is no longer 'ill'.

(2) The apparent belief that caring parents live as long as their ailing offspring.

(3) The persistent belief-given currency in Eason and Grimes's 1976 forecast-that the accretion of new long-stay patients is rapidly declining; whereas the national average has varied little since 1974 (in spite of the marked increase in refusal by some consultants to admit anyone likely to become long-stay). In some districts it appears that discharges and deaths of new long-stay in-patients approximately balance intake to the category; so that the number of such in-patients will remain approximately constant unless policies or demographic facts change.

In other districts, admission and discharge policies may lead to a declining new long-stay in-patient population. This does not mean that there are fewer long-term patients; it means that the number not in hospital is increasing.

\section{Autism Research Database}

A new information retrieval service covering research on autism has been set up to assist research workers and those involved in the care and teaching of autistic people. Details of over 600 publications on autism and related topics are currently held on the National Autistic Society's computer at Sunderland Polytechnic. This database is updated continuously to include new work as soon after publication as possible. It is hoped that it will eventually be possible to provide on-line or dial-up access, but for the present access has to be through the operators.

Information is available in two forms: for those with a general interest in autism research, Titles in Autism, a listing of the most recent additions to the database, will be produced bimonthly. Copies of the first issue (April 1985), which lists
1984 and early 1985 publications, are available. Specific questions will be dealt with on an individual basis. The information retrieval system is flexible and is able to carry out topic searches using keyword lists and to cross-reference subjects and/or other information. Abstracts (100-150 words) will also be supplied on request.

In order that abstract and keyword lists can be kept as up to date as possible, it would be helpful if authors could send reprints of any articles on autism or related topics as soon as they are published. Information and enquiries: Anne P. Humphreys or Ian Carr, Autism Research Unit, Department of Pharmaceutical Chemistry, Faculty of Pharmaceutical Sciences, Sunderland Polytechnic, Sunderland SR1 3SD (telephone: Sunderland (0783) 76191 Ext. 36).

\section{Miss S. I. McClean's Trust}

There exists at Burley-in-Wharfedale, West Yorkshire, a small endowment fund provided by the Will of the late Miss Sarah Isabella McClean, who died in 1934. The income from the Charity is to be applied by the Trustees in relieving, in cases of need, medical practitioners who are suffering from mental illness and who require hospital (including outpatient) treatment or by providing or paying for items, services or facilities calculated to alleviate suffering or assist recovery, but which are not readily available from other sources. The funds are not to be applied directly in relief of rates, taxes or other public funds, but may be used for supplementing relief or assistance so provided. Any applications for consideration by the Trustees should be made in the first instance to Messrs. Ford \& Warren, Solicitors, 5 Park Square, Leeds LS1 2AX (telephone: Leeds 436601). 